\title{
Role of Three-dimensional Power Doppler Angiography in Assessment of Perifollicular Ovarian Vascularity in Patients Undergoing In Vitro Fertilization: A Single Center Experience
}

\author{
${ }^{1}$ Kunur Shah, ${ }^{2}$ Vineet Mishra, ${ }^{3}$ Sugandha Goel, ${ }^{4}$ Rohina Aggarwal, ${ }^{5}$ Sumesh Choudhary, ${ }^{6}$ Khushali Gandhi
}

\begin{abstract}
Introduction: Ovarian blood flow plays a vital role in ovarian follicular development in In Vitro fertilization (IVF) cycle. Perifollicular color mapping with three-dimensional (3D) power Doppler angiography (PDA) is a reliable technique for predicting IVF success.
\end{abstract}

Objective: Single-center prospective study, with an aim to investigate correlation between 3D PDA parameters and success of IVF cycles.

Methods: Ovulation induction was done using a long protocol with gonadotrophins and $\mathrm{GnRH}$ agonist in 94 infertile women. With the help of 3D PDA, on the day of HCG administration, ovarian volume (OV), number of follicles (NF), vascularization index (VI), flow index $(\mathrm{FI})$ and vascularization flow index $(\mathrm{VFI})$ were calculated. The success of IVF outcome in these patients was noted.

Results: The OV, VI, FI, VFI, and NF were significantly higher in women who conceived following IVF. IVF outcome can be presumed by NF and VI. NF was the only independent parameter predicting a number of retrieved oocytes, mature oocytes, fertilized oocytes and number of grade 4 embryos.

Conclusion: Three-dimensional USG and PDA is an easy and quick modality for ovarian blood flow assessment and prediction of success of IVF cycle. Positive correlation was identified between 3D PDA parameters and IVF laboratory parameters along with subsequent IVF success.

Keywords: IVF outcome; Number of follicles; Power doppler angiography, Three dimensional

How to cite this article: Shah K, Mishra V, Goel S, Aggarwal R, Choudhary S, Gandhi K. Role of Three-dimensional Power Doppler Angiography in Assessment of Perifollicular Ovarian Vascularity in Patients Undergoing In Vitro Fertilization: A Single Center Experience. Donald School J Ultrasound Obstet Gynecol 2018;12(3):162-167.

Source of support: Nil

Conflict of interest: None

\footnotetext{
${ }^{1,6}$ Assistant Professor, ${ }^{2}$ Professor and HOD, ${ }^{3}$ Ex. Clinical Fellow, ${ }^{4}$ Professor, ${ }^{5}$ Associate Professor

${ }^{1-6}$ Department of Obstetrics and Gynaecology, Institute of Kidney Diseases and Research Centre, Asarwa, Ahmedabad, Gujarat, India
}

Corresponding Author: Vineet Mishra, Professor and HOD Department of Obstetrics and Gynaecology, Institute of Kidney Diseases and Research Centre, Asarwa, Ahmedabad, Gujarat, India, e-mail: drkunurshah22@yahoo.co.in

\section{INTRODUCTION}

Last two decades have witnessed the great advances in IVF and has also identified knowledge deficits in some areas. In spite of having multiple IVF centers, there is a scarcity of national data quoting of the overall success rate of IVF in India. The need to search for a predictor of IVF cycle is as old as the discovery of IVF. Various factors are used to predict the success of IVF cycle like maternal age, basal FSH, anti mullerian hormone (AMH), body mass index (BMI), antral follicle counts etc. ${ }^{1}$ A study on ovarian markers of implantation potential proved that expression of 11-beta hydroxy dehydrogenase steroidby granulosa cell in vitro, adhesion and proliferation of cumulus cells in vitro, steroidogenic activity of cumulus cells in vitro, vascular endothelial growth factors bound to granulosa and cumulus cells and perifollicular vascularity may have vital role to play in predicting implantation. ${ }^{2}$ Any method that helps in predicting IVF success before oocyte retrieval will help in counseling the couple before undergoing the procedure.

Ovarian blood flow (OBF) has a vital role to play in the selection and maturation of dominant follicle. ${ }^{3,4}$ In previous few years, OBF was evaluated by pulse Doppler. Vascularity of preovulatory follicle was more extensive than other follicles and, peak systolic velocity of follicles was significantly correlated with oocyte recovery and quality of embryos. ${ }^{5}$ The study of Coulam et al. on qualitative and quantitative assessment of follicular blood flow concluded that women with atleast one follicle having PSV $\geq 10 \mathrm{~cm} / \mathrm{s}$ on the day of HCG administration has more chances of conception than those with PSV $<10 \mathrm{~cm} / \mathrm{s}(\mathrm{p}=0.05){ }^{6}$

Color Doppler requires selection of a large vessel because of its inherent less sensitivity to smaller blood vessels. ${ }^{7-9}$ Benefits of power doppler over color doppler include, there is no aliasing, higher sensitivity leading to better identification of smaller vessels and no need for angle correction. ${ }^{10}$ There were several studies subjectively and objectively assessing the role of power Doppler in predicting the success of IVF outcome. ${ }^{11,12}$ Power Doppler gives information about blood flow in a 2D plane which was overcome by 3D PDA. 
Power Doppler is more sensitive, while 3D ultrasound gives spatial awareness and both of these advantages are provided with 3D PDA which gives an idea about the blood flow of the whole organ. ${ }^{13}$ With the help of "virtual organ computer-aided analysis (VOCAL $\left.{ }^{\mathrm{TM}}\right) "$ software, one can manually define the target volume and quantify the blood flow using histogram facility. ${ }^{14,15} \mathrm{It}$ measures three important parameters named VI showing the percentage of a number of blood vessels in the area, FI showing blood flow intensity in the area, VFI includes both and represents total tissue perfusion. ${ }^{16}$ There is good evidence proving inter- and intra-observer reproducibility of the technique. ${ }^{9,10,17}$

Various studies have been performed on identifying the role 3D PDA in predicting IVF success. No significant variation was observed by Anita et al. in implantation, clinical pregnancy and live birth rates, with or without perifollicular vascularity, in poor responders. ${ }^{18}$ Significantly higher 3D PDA parameters were observed by Pan et al. in PCO patients. ${ }^{19}$ Kupesic et al. proved ovarian stromal FI and total ovarian volume as a predictor of favorableIVF outcome. ${ }^{1}$ Merce et al. predicted $76 \%$ of pregnancies in IVF patients with the help of ovarian FI and number of grade 1 embryos. ${ }^{16}$

The aim of this prospective study was to identify the relation between the NF, total OV and 3D PDA parameters (VI, FI, VFI) after stimulation with gonadotrophins with IVF laboratory parameters and IVF outcome.

\section{METHODS}

Study Design: Prospective interventional study.

Study Period: September 2015 to August 2016.

Sample Size: Single-center prospective study of 94 infertile women coming to the OPD of the Department of Obstetrics and Gynecology. Institutional ethical committee approval was obtained.

\section{Inclusion Criteria}

- Age less than 38 years

- Regular menstrual cycles

- Day 2/3 FSH level < $10 \mathrm{~mL}$ U/L

- BMI within normal limits (18.9 - 24.9)

- Nonsmokers

\section{Exclusion Criteria}

- Clinical, ultrasonographic or biochemical features suggestive of PCOS

- Endometriosis

- Patients with a history of complete or partial oophorectomy due to any reason

- Patients not willing to give consent to participate in the study
All patients undergoing their first IVF cycle with long (GnRH agonist) protocol were included in the study after obtaining informed consent. All women were given monophasic oral contraceptive pills from day 2 of the menstrual cycle and Gn RH agonist Injection Leuprolide Acetate (Luprorin-4, $4 \mathrm{mg} / 4 \mathrm{~mL}$ vial, Intas)was started from day 21 of the previous cycle in the dose of $0.5 \mathrm{mg}$ subcutaneously daily. Pituitary down-regulation was confirmed by the presence of follicle $<10 \mathrm{~mm}$ and thickness of endometrium $<5 \mathrm{~mm}$ on Day 2 of the cycle. After performing, Day 2 transvaginal sonography, patients received recombinant FSH $225 \mathrm{IU} / \mathrm{mL}$ (Newmon-R, LG Life Sciences)intramuscular per day and was adjusted as per follicular growth. In 34 cycles, HMG (IVF-M, LG Life Sciences) was also added to achieve adequate follicular growth. When three lead follicles were exceding $18 \mathrm{~mm}$ diameter, recombinant HCG (Ovitrelle, Merck Serono) was administered in a dose of $250 \mathrm{mcg}$, two injections subcutaneously.

All Doppler ultrasound examinations were conducted on the day of HCG administration by a single observer (K.N.S.) by Voluson E8 (GE Medical System, Milwaukee, WI, USA) with RIC 6-12-D, 5-13 MHz vaginal probe. The maximum diameter of all follicles of $>10 \mathrm{~mm}$ was measured. Endometrial thickness was also measured in a sagital section of the uterus. Power Doppler was activated, and the window was adjusted to include the whole ovarian area. Following parameters were set and kept constant for every patient. Color gain -6.0 to -8.0 , pulse repetition frequency (PRF) $600 \mathrm{~Hz}$ and wall motion filtered $50 \mathrm{~Hz}$. Then 3D was activated and region of interest was adjusted to include entire ovary with volumetric sector angle 90 degrees. The patient was asked to avoid movement while the image was acquired as well as the movement of the probe was also avoided. In the cases where motion artifacts were detected, examinations were repeated after explaining the patients.

The analysis was done using the VOCAL program. Manual mode was used checking six slices at 30 degrees, 3D Power Doppler indices were calculated using volume histogram. Ovarian volume, number of follicles, VI, FI, VFI, were included as main outcomes. The sum of data from both the sides was taken for analysis as there was no statistically significant difference in the parameters of both ovaries.

Oocyte retrieval under transvaginal sonography (TVS) guidance was done 36 hours post HCG injection. Oocytes were categorized as mature and immature according to the stage of development. Oocytes were fertilized by IVF. UK NEQAS embryo morphology scheme was used to grade embryos. ${ }^{20}$

One to three embryos were transferred on Day 3 (72 hours after oocyte retrieval) under transabdominal USG guidance. All the patients undergoing embryo 
transfer had an endometrial thickness of 7 to $9.5 \mathrm{~mm}$. Micronized progesterone $600 \mathrm{mg}$ (Susten300, Sun Pharma) was given to all patients starting from the day of oocyte retrieval. All patients received recombinant HCG (OVITRELLE, Merck Serono ) twice a week from the day of embryo transfer till 14 days. Serum beta-HCG concentration was recorded 14 days following embryo transfer. Clinical pregnancy was defined as the presence of one or more gestational sac with cardiac activity.

\section{Statistical Analysis}

Data are entered into the SPSS V 20 and analysis has been conducted.

Continuous data are expressed as Mean \pm Standard form, and Non-continuous data are expressed as in frequency and in percentages form.

For Continuous data, it follows both parametric as well as Non-parametric distribution.

Independent $t$-test and Mann Whitney test have been used for carrying out significant value.

For Non- continuous data, Chi-Square test and Fisher exact test have been used for carrying out significant value.i.e. $p$-value.

\section{RESULTS}

We analyzed 94 women undergoing IVF treatment at our center. Mean age was $30.75 \pm-4.11$ years with rage from 21 to 38 years. The mean duration of infertility was $4.52 \pm$ 1.68 years with a rang e from 2 to 7 years. 51 cases were attributed to primary infertility, and 43 cases were due to secondary infertility. The reason of infertility was a tubal factor in 26 cases, male factor in 10 cases, ovarian causes in 49 cases, mixed causes in 3 and unexplained in 6 cases. Fourty-four patients $(46.80 \%)$ had positive beta HCG on day 15 after embryo transfer. There were total 31 clinical pregnancy $(32.97 \%)$ with 7 twins $(22.58 \%)$ and 5 triplet $(16.12 \%)$ pregnancies. Ten pregnancies aborted (10.62\%). Three patients had ectopic pregnancies (3.19\%).

Table 1 compares general and demographic parameters of pregnant and non-pregnant patients including age, cause, and type of infertility, a dose of recombinant FSH and HMG required to achieve adequate stimulation and duration of stimulation. Mean age of patients who conceived was significantly lower than patients who didn't conceive. Cause and type of infertility, the duration of stimulation and dose of gonadotrophins had no significant impact on the success of the IVF cycle.

It is depicted in Table 2, that, number of mature oocytes, no. of fertilized oocytes and the total number of embryos available on the day of transfer, number of embryo transferred and the total number of grade 4 embryo transferred were significantly more in women who conceived as compared to those who did not. All embryo transfers were done on day 3. Women who
Table 1: General and demographic profile of patients

\begin{tabular}{llll}
\hline & $\begin{array}{l}\text { Pregnant } \\
(n=31)\end{array}$ & $\begin{array}{l}\text { Non-pregnant } \\
(n=63)\end{array}$ & $p$ value \\
\hline Age $(\mathrm{yrs})$ & & $31.7 \pm 4.14$ & $0.04^{*}$ \\
$\begin{array}{l}\text { Mean } \pm \text { SD } \\
\text { Type of infertility }\end{array}$ & $29.81 \pm 4.08$ & & \\
Primary & $25(80.65 \%)$ & $51(80.95 \%)$ & $1.00(\mathrm{NS})$ \\
Secondary & $6(19.35 \%)$ & $12(19.05 \%)$ & \\
Etiology of & & & \\
infertility & & & \\
Male factor & $4(12.90 \%)$ & $6(9.52 \%)$ & $0.72(\mathrm{NS})$ \\
Tubal factor & $8(25.81 \%)$ & $18(28.57 \%)$ & $0.78(\mathrm{NS})$ \\
Ovarian & $16(51.61 \%)$ & $33(52.38 \%)$ & $1.00(\mathrm{NS})$ \\
Mixed & $1(3.23 \%)$ & $2(3.17 \%)$ & $1.00(\mathrm{NS})$ \\
Unexplained & $2(6.45 \%)$ & $4(6.35 \%)$ & $1.00(\mathrm{NS})$ \\
Total dose of & $2394.84 \pm$ & $2297.14 \pm$ & $0.2469(\mathrm{NS})$ \\
FSH & 670.87 & 637.21 & \\
Total dose of & $2286.74 \pm$ & $2422.67 \pm$ & $0.344(\mathrm{NS})$ \\
HMG & 522.88 & 455.82 & \\
Days of & $9.4 \pm 1.5$ & $8.9 \pm 1.3$ & $0.09(\mathrm{NS})$ \\
stimulation & & & \\
\hline
\end{tabular}

* shows statistically significant difference between the groups; $p$ value $<0.05$ is considered to be statistically significant; NS shows non-significant difference between the groups

conceived had higher numbers of grade 4 embryo transferred.

Table 3 shows the relation between 3D power Doppler Angiographic parameters including a total number of follicles, total ovarian volume, VI, FI, VFI on the day of HCG injection and IVF cycle results. The number of follicles, total ovarian volume, VI, FI, VFI were significantly elevated in women who conceived.

Table 4 describes correlation between USG parameters and IVF laboratory outcomes. All parameters were showing positive linear co-relation with highest $(\mathrm{r}=0.7058)$ between number of follicles and number of oocyte retrieved followed by number of follicles and number

Table 2: Relationship between clinical and IVF laboratory parameters with IVF results

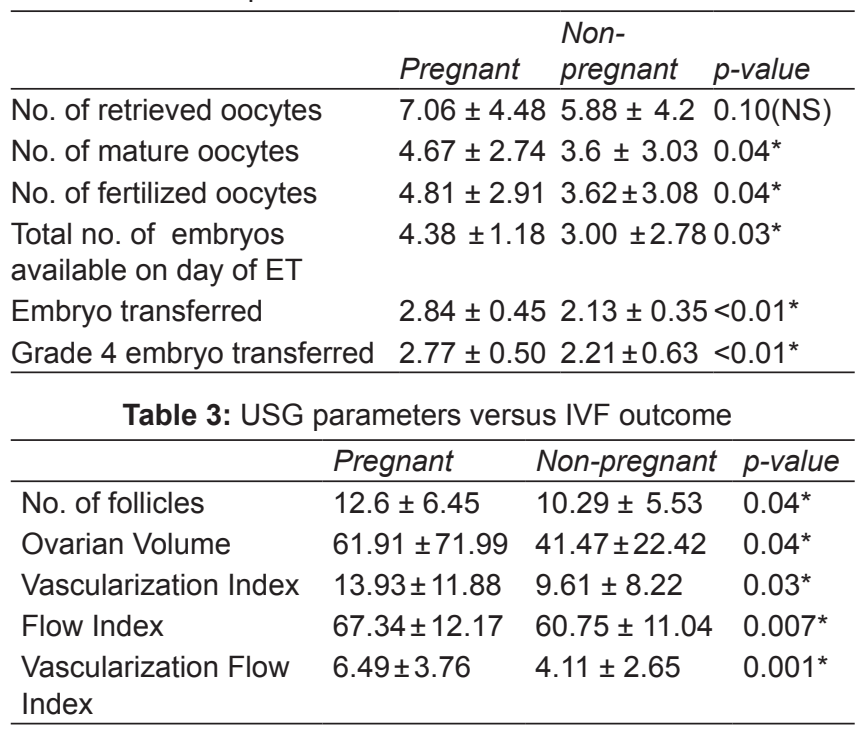


Role of Three-dimensional Power Doppler Angiography in Assessment of Perifollicular Ovarian Vascularity in Patients

Table 4: Correlation between USG and IVF laboratory parameters*

\begin{tabular}{llllll}
\hline Correlation & OV & NF & VI & FI & VFI \\
\hline $\begin{array}{l}\text { No. of retrieved } \\
\text { oocytes }\end{array}$ & 0.2373 & 0.7058 & 0.1930 & 0.2601 & 0.0787 \\
$\begin{array}{l}\text { No. of mature } \\
\text { oocytes }\end{array}$ & 0.2459 & 0.6622 & 0.1977 & 0.1851 & 0.0221 \\
$\begin{array}{l}\text { No. of fertilized } \\
\text { oocytes }\end{array}$ & 0.2398 & 0.7021 & 0.1789 & 0.1290 & 0.0247 \\
$\begin{array}{l}\text { No. of embryos } \\
\text { transferred }\end{array}$ & 0.0873 & 0.3669 & 0.0578 & 0.1333 & 0.0285 \\
$\begin{array}{l}\text { No. of grade } \\
\begin{array}{l}\text { embryos } \\
\text { transferred }\end{array}\end{array}$ & 0.0902 & 0.3566 & 0.0542 & 0.1318 & 0.0256 \\
\hline
\end{tabular}

*Pearson Correlation is used

of mature oocytes $(r=0.7021)$. Number of follicles was significantly co-related with $\mathrm{VI}(\mathrm{r}=0.28, \mathrm{p}<0.01)$, $\mathrm{FI}(\mathrm{r}=0.23$, $\mathrm{p}=0.03)$ and $\operatorname{VFI}(\mathrm{r}=0.31, \mathrm{p}<0.01)$; in contrast to ovarian volume $(\mathrm{OV})$ which did not significantly co-relate with $\mathrm{VI}$ $(\mathrm{r}=0.04, \mathrm{p}=0.69)$, FI $(\mathrm{r}=0.12, \mathrm{p}=0.25)$ and VFI $(\mathrm{r}=0.09$, $\mathrm{p}=0.04)$.

Table 5 clearly highlights regression analysis to identify 3D PDA parameter predicting the IVF laboratory parameters, that number of follicles was the only independent parameter predicting number of retrieved oocytes $(\mathrm{r}=0.705, \mathrm{p}<0.01)$, number of fertilized oocytes $(\mathrm{r}=0.701$, $\mathrm{p}<0.01)$, number of mature oocytes $(\mathrm{r}=0.662, \mathrm{p}<0.01)$ and number of grade 4 embryos $(r=0.357, \mathrm{p}<0.01)$.

Table 5: Regression analysis to predict IVF laboratory parameters*

\begin{tabular}{|c|c|c|c|c|c|c|c|}
\hline & $B$ & $S E$ & $\beta$ & $t$ & $p$ & $R$ & $\begin{array}{l}\text { Adj. } \\
R 2\end{array}$ \\
\hline $\begin{array}{l}\text { No. of } \\
\text { retrieved } \\
\text { oocytes }\end{array}$ & & & & & & 0.705 & 0.491 \\
\hline Constant & 0.682 & 0.662 & & 1.031 & 0.305 & & \\
\hline NF & 0.509 & 0.053 & 0.705 & 9.533 & $<0.01^{*}$ & & \\
\hline $\begin{array}{l}\text { No. of } \\
\text { mature } \\
\text { oocytes }\end{array}$ & & & & & & 0.662 & 0.432 \\
\hline Constant & 0.379 & 0.478 & & 0.793 & 0.430 & & \\
\hline NF & 0.327 & 0.039 & 0.662 & 8.464 & $<0.01^{*}$ & & \\
\hline $\begin{array}{l}\text { No. of } \\
\text { fertilized } \\
\text { oocytes }\end{array}$ & & & & & & 0.701 & 0.487 \\
\hline Constant & 0.089 & 0.470 & & 0.189 & 0.850 & & \\
\hline NF & 0.358 & 0.038 & 0.701 & 9.440 & $<0.01^{*}$ & & \\
\hline $\begin{array}{l}\text { Embryos } \\
\text { on } \\
\text { transfer } \\
\text { day }\end{array}$ & & & & & & 0.367 & 0.126 \\
\hline Constant & 2.349 & 0.185 & & 12.707 & $<0.01$ & & \\
\hline NF & 0.057 & 0.015 & 0.367 & 3.789 & $<0.01^{*}$ & & \\
\hline $\begin{array}{l}\text { Grade } 4 \\
\text { embryos } \\
\text { on day of } \\
\text { ET }\end{array}$ & & & & & & 0.357 & 0.118 \\
\hline Constant & 12.332 & 0.187 & & 12.499 & $<0.01$ & & \\
\hline NF & 0.055 & 0.015 & 0.357 & 3.668 & $<0.01^{*}$ & & \\
\hline
\end{tabular}

*Linear Regression is used
Table 6: Logistic regression to predict success of IVF*

\begin{tabular}{lllllll}
\hline & $B$ & $S E$ & Wald & $d f$ & $p$ & Exp (B) \\
\hline $\mathrm{NF}$ & -0.121 & 0.053 & 5.194 & 1 & $0.023^{*}$ & 0.886 \\
$\mathrm{OV}$ & 0.005 & 0.008 & 0.416 & 1 & 0.519 & 1.005 \\
$\mathrm{VI}$ & 0.130 & 0.053 & 6.085 & 1 & $0.014^{*}$ & 1.139 \\
$\mathrm{FI}$ & 0.020 & 0.024 & 0.708 & 1 & 0.400 & 1.021 \\
$\mathrm{VFI}$ & -0.255 & 0.138 & 3.382 & 1 & 0.066 & 0.775 \\
Number & 0.552 & 0.289 & 3.647 & 1 & 0.056 & 1.737 \\
of grade 4 & & & & & & \\
embryos & & & & & & \\
transferred & \multicolumn{7}{c}{ Constant } & -1.790 & 1.555 & 1.325 & 1 & 0.250 & 0.167 \\
"Binomial Logistic Regression is used & & &
\end{tabular}

In Table 6, the logistic regression analysis was done among OV, VI, FI, VFI, and number of grade 4 embryos transferred to identify the best predictor of IVF success. VI $(p=0.014)$ and NF $(p=0.02)$ are the best predictors of successful IVF outcome followed by number of grade 4 embryos transferred $(p=0.056), \mathrm{VFI}(\mathrm{p}=0.066), \mathrm{FI}(\mathrm{p}=0.40)$ and OV $(p=0.519)$.

\section{DISCUSSION}

Despite extensive literature search, we were able to identify only a few studies where 3D PDA is used to evaluate blood flow of ovary in patients undergoing IVF and also to co-relate its impact on successful IVF outcome. Previous studies have calculated PSV from many follicles ${ }^{21}$ or maximum PSV of the dominant follicle by serial assessment. ${ }^{5}$ Color Doppler evaluation of follicular blood flow was dependent upon subjective identification of peri-follicular blood vessel by sonographer followed by correction of insonation angle.

In this study, 3D PDA was used to demonstrate the dynamic vascularity of ovary before oocyte retrieval. It can measure blood flow in total ovarian volume conveniently, accurately and rapidly using VOCAL software and overcomes the angle dependence and aliasing of color Doppler. ${ }^{21,22}$ Three-dimensional power Doppler histogram can quantify the blood flow of ovarian stromal Doppler signal via 3D reconstructive figure. ${ }^{23}$

As in the formula defined by Pairleitner et al.,${ }^{24} \mathrm{VI}$ denotes the ratio of color-coded voxels to all voxels within the volume and is expressed as a percentage which indicates the proportion of flow signal (vessel density) detected within the total ovary. The FI represents the mean power Doppler signal intensity from all color-coded voxels which means the average value of the flow intensity inside the whole ovary. VFI demonstrates both vessels and flows intensity derived by multiplying the VI and FI.

The correlation between NF's $>10 \mathrm{~mm}$ on the day of HCG administration and number of oocytes retrieved, the number of mature oocytes, number of fertilized oocytes 
and the number of embryos transferred and number of grade 4 embryos were found to be of highest significance. Stepwise multiple regression analysis identified NF as an independent variable predicting a number of oocytes retrieved. Equivalent outcomes were demonstrated with bi-dimensional USG by Wittmack et al., Dubey et al., and Bergh et al. ${ }^{25-27} \mathrm{NF}, \mathrm{OV}, \mathrm{VI}, \mathrm{FI}$, and VFI showed linear positive correlation with biological parameters of IVF.Consequently, embryo quality can be presumed by assessing perifollicular ovarian vascularity.

The comparison was done between pregnant and non-pregnant groups to identify parameters that were significant and also to determine predictors affecting oocyte retrieval and IVF outcomes. Among them, only age was found to be lower in those who conceived. As the patient's age increases,there was a decrease in ovarian response, ovarian volume, and antral follicle count. ${ }^{28}$ Besides, no other characteristics had any significance. The $\mathrm{OV}$ and the 3D PDA indices (VI, FI, and VFI) were found to be higher in the pregnant group as compared with the non-pregnant group.The same results were obtained by Merce et al. ${ }^{16}$

Kupesic et al. ${ }^{28}$ have shown that the ovarian stromal flow index (FI) after pituitary down-regulation was higher among patients who became pregnant.Jarvela et al. described IVF-induced changes in ovarian vascularization and compared normal with polycystic ovaries (PCOS) in 60 infertile patients after measuring parameters on the day of pituitary down-regulation, FSH stimulation, and HCG injection using 3D PDA. ${ }^{29}$ They observed that VI and VFI were higher in pregnant women as compared with non-pregnant women. ${ }^{29}$

The quality of the embryos transferred is an important predictor of successful IVF outcome. In our observation, women who conceived had higher numbers of grade 4 embryos transferred as compared to those who did not. This was consistent with Philippe et al., who identified embryo quality as a better predictor than its number and women's age for favorable IVF outcome. ${ }^{30}$

Logistic regression analysis of variables showing significant differences between the pregnant and nonpregnant clusters (OV, VI, FI and VFI, number of grade 4 transferred embryos) helped in identifying the predictor of IVF success. NF and VI were the best predictors for successful IVF outcome followed by a number of grade 4 embryos transferred and VFI. This was slightly different from Merece et al. ${ }^{16}$ who identified FI and number of grade 1 embryo transferred as the best predictors.

\section{CONCLUSION}

Three-dimensional PDA has proved to be an easy and accurate method of assessing ovarian blood flow. We could identify positive co-relation between 3D PDA parameters and IVF laboratory parameters. This study proved a number of follicles as the only independent parameter, NF and VI as the best predictors of successful IVF outcome. Better quality of embryos transfered also improves results. These findings are similar with current knowledge which supports routine utilization of this technique to counsel the patients before oocyte retrieval. In view of a higher number of multiple pregnancies in our study, further study is required to comment on decreasing the number of embryo transferred in women with high perifollicular VI, FI, and VFI to reduce subsequent higher order multiple births. Thus, 3D PDA provides valuable help in managing IVF patient and is worthy of further larger studies.

\section{REFERENCES}

1. Kupesic S, KurjakA. Predictors of IVF outcome by threedimensional ultrasound.Human Reprod. 2002;17(4):950.

2. Linda G. Ovarian markers of implantation potential in assisted reproduction. Human Reprod. 1998; 13: Supp 4.

3. Abulafia O, Sherer DM. Angiogenesis of the ovary. Am J ObstetGynecol. 2000;182: 240-246.

4. Augustin HG. Vascular morphogenesis in the ovary. Baillieres Best Pract Res ClinObstetGynaecol. 2000;14: 867-882.

5. Nargund G, Doyle PE, Bourne TH, Parsons JH, Cheng WC, Campbell $\mathrm{S}$, Collins WP.Ultrasound derived indices of follicular blood flow before HCG administration and the prediction of oocyte recovery and preimplantation embryo quality. HumanReprod. 1996;11(11):2512-2517.

6. Coulam CB, Goodman C, Rinehart JS.Colour Doppler indices of follicular blood flow as predictors of pregnancy after invitro fertilizationand embryo transfer. HumanReprod. 1999; 14:1979-1982.

7. Vieli A. Ultrasonic Doppler and duplex systems: possibilities and limitations. Urol. 1990; 45: 251-257.

8. Nelson TR, Pretorius DH. The Doppler signal: where does it come from and what does it mean? AJR Am J Roentgenol. 1988; 151:439-447.

9. Raine-Fenning NJ, Campbell BK, Clewes JS, Kendall NR, Johnson IR. The reliability of virtual organ computer-aided analysis(VOCAL) for the semiquantification of ovarian, endometrialandsubendometrial perfusion. Ultrasound ObstetGynecol. 2003; 22: 633-639.

10. Jarvela IY, SladkeviciusP,Tekay AH, Campbell S, NagundG. Intraobserver and interobserver variability of ovarian volume, gray-scale and color flow indices obtained usingtransvaginal three-dimensional power doppler ultrasonography. Ultrasound ObstetGynecol. 2003; 21:277-282.

11. Bhal PS, PughND, Chui DK, Gregory L, Walker SM, Shaw RW.The use of transvaginal power doppler ultrasonography to evaluate the relationship between perifollicular vascularity and outcome in in-vitro fertilization treatment cycles. Human Reprod. 1999;14:939-945.

12. Chui DK, Pugh ND, Walker SM, Gregory L, Shaw RW. Follicular vascularity - The predictive value of transvaginal power doppler ultrasonography in an in-vitro fertilization programme: a preliminary study. HumanReprod. 1997;12: 191-196. 
13. N. J.Raine-Fenning, B. K. Campbell, J. S. Clewes, N. R. Kendall and I. R. Johnson, The interobserver reliability of three-dimensional power Doppler data acquisition within the female pelvis, Ultrasound Obstet Gynecol 2004;23:501-508.

14. Raine-Fenning NJ, CampbellBK,Collier J, Brincat MB, Johnson IR. The reproducibility of endometrial volume acquisitionand measurement with the VOCAL-imaging program. Ultrasound Obstet Gynecol. 2002;19:69-75.

15. Bordes A, Bory AM, Benchaib M, Rudigoz RC, Salle B. Reproducibility of transvaginal three-dimensional endometrial volume measurements with virtual organ computer-aided analysis(VOCAL) during ovarian stimulation. Ultrasound Obstet Gynecol. 2002;19:76-80.

16. Merce LT, Santiago B, María JB, Juan T, Rosina G, Florencia $\mathrm{S}$, Amelia V. Assessment of the ovarian volume, number and volume of follicles and ovarian vascularity by three-dimensional ultrasonography and power doppler angiography on the HCG day to predict the outcome in IVF/ICSI cycle. Human Reprod. 2006;21(5):1218-1226.

17. MerceLT, Gomez B, Engels V, Bau S, BajoJM.Intraobserver and interobserver reproducibility of ovarian volume, antral follicle count and vascularity indices obtained with transvaginal 3-dimensional ultrasonography, power dopplerangiography and virtual organ computer-aided imaging program. J Ultrasound Med. 2005;24:1279-1287.

18. Anita K, Ernest Hung Yu Ng1, William BY, Pak CH. Perifollicular vascularity in poor ovarian responders during IVF. Human Reprod. 2006;21(6): 539-544.

19. Pan HA, Wu MH, Cheng YC, Li CH, Chang FM. Quantification of doppler signal in PCOS using three-dimensional power doppler ultrasonography: A possible new marker for diagnosis. HumanReprod. 2002;17:201-206.

20. Cutting et al. Modified for UK NEQAS Embryo Morphology Scheme 2010 - Elective Single Embryo Transfer: Guidelines for Practice. British Fertility Society and Association of Clinical Embryologists. Human Fertility. 2008;11(3):131-146.
21. Balakier H, StronellR.ColourDoppler assessment of the GnRHa - The RI value seems to reflect this sensitivity: Folliculogenesis in invitro fertilization patients. FertilSteril.1994;62:1211-1216.

22. Wu MH, Tang HH, Hsu CC, Wang ST, Huang KE. The role of three-dimensional ultrasonographic images in ovarian measurement. Fertil Steril.1998;69:1152-1155.

23. Dolz M, Osborne NG, Blanes J, Raga F, Abad-Velasco L, Villalobos A, Pellicer A, Bonilla-Musoles F. Polycystic ovarian syndrome: Assessment with color doppler angiography and three-dimensional ultrasonography. J Ultrasound Med. 1999;18:303-313.

24. Pairleitner H, Steiner H, Hasenoehrl G, Staudach A. Threedimensional power doppler sonography: Imaging and quantifying blood flow and vascularization. Ultrasound ObstetGynecol. 1999;14:139-143.

25. Wittmaack FM, Kreger DO, Blasco L, Tureck RW, MastroianniL, Lessey BA. Effect of follicular size on oocyte retrieval, fertilization, cleavage and embryo quality in invitro fertilization cycles: A 6-year data collection.FertilSteril. 1994;62:1205-1210.

26. Dubey AK, Wang HA, Duffy P, Penzias AS. The correlationbetween follicular measurements, oocyte morphology and fertilization ratesin an invitro fertilization program. FertilSteril. 1995;64:787-790.

27. Bergh C, Broden H, Lundin K, Hamberger L. Comparison of fertilization, cleavage and pregnancy rates of oocytes from large and small follicles.HumanReprod.1998;13:1912-1915.

28. Kupesic S, KurjakA, Bjelos D, Vujisic S. Three-dimensional ultrasonographic ovarian measurements and invitrofertilization outcome are related to age. FertilSteril. 2003;79:1.

29. Jarvela IY, Sladkevicius P,Kelly S, OjhaK,Campbell S, NargundG. Comparison of follicular vascularization in normal versus polycystic ovaries duringinvitro fertilization as measured using 3D PDA. FertilSteril. 2004;82:5.

30. Terriou P, SapinC, Giorgetti C, HansE,SpachJL,Roger R. Embryo score is a better predictor ofpregnancy than the number of transferredembryos or female age. FertilSteril. 2001;75:3. 